\title{
Optical Gas Sensing Using Gold Nanoparticles/Polyelectrolyte Layer-by-Layer Films: A Case Study with Poly(acrylic acid) for Ammonia Detection
}

\author{
Tao Wang, Takuya Okada, Kenshi Hayashi, ${ }^{1}$ Stephen W. James, ${ }^{2}$ and Seung-Woo Lee* \\ Graduate School of Environmental Engineering, The University of Kitakyushu, \\ 1-1 Hibikino, Kitakyushu 808-0135, Japan \\ ${ }^{1}$ Graduate School of Information Science and Electrical Engineering, Kyushu University, \\ 744 Motooka, Fukuoka 819-0395, Japan \\ ${ }^{2}$ Department of Engineering Photonics, School of Engineering, Cranfield University, \\ Cranfield, Bedford MK43 0AL, UK
}

(Received October 13, 2015; accepted November 26 2015)

Keywords: gold nanoparticles, surface plasmon resonance (SPR), ammonia, polyelectrolyte, layer-bylayer (LbL) deposition

In this study, we demonstrated a new approach for gas sensing using multilayer films selfassembled with cationic gold nanoparticles $\left(\mathrm{AuNPs}^{+}\right)$and anionic polyelectrolytes via layerby-layer (LbL) deposition. The surface of $\mathrm{AuNPs}^{+}$was modified with a cationic disulfide, $\left[-\mathrm{S}\left(\mathrm{CH}_{2}\right)_{2} \mathrm{NHCO}\left(\mathrm{CH}_{2}\right)_{10}\left(\mathrm{CH}_{3}\right)_{3} \mathrm{~N}^{+} \mathrm{Br}^{-}\right]_{2}$. Two types of LbL film using AuNPs ${ }^{+}$were selfassembled with anionic polyelectrolytes, poly(acrylic acid) (PAA), and poly(sodium 4-styrene sulfonate) (PSS) on quartz substrates, and their film growth was confirmed by UV-vis measurements. The 10-cycle AuNPs ${ }^{+} / \mathrm{PAA}$ film showed reproducible responses after exposure to ammonia gas $(3000 \mathrm{ppm})$ and $\mathrm{HCl}$ treatment $(0.1 \mathrm{M})$, showing absorbance changes of $0.0428 \pm 0.0033$ at $299 \mathrm{~nm}$ and $0.0053 \pm 0.0013$ at $544 \mathrm{~nm}$ for five repeated tests. On the other hand, no significant changes were observed for the 10-cycle AuNPs ${ }^{+} / \mathrm{PSS}$ film. Ammonia binding was based on the acid-base interaction between ammonia and the free carboxylic acid groups of PAA. The film's composition and morphology were also investigated by Fourier transform infrared spectroscopy (FTIR) and atomic force microscopy (AFM) measurements to clarify the sensing mechanism.

\section{Introduction}

In recent years, there has been considerable interest in the facile, low-cost fabrication of nanothin films for the purpose of biochemical sensing because they are advantageous for ensuring the efficient adsorption of target analytes. ${ }^{(1)}$ Several approaches for the deposition of organized molecular films have been examined, such as Langmuir-Blodgett (LB), ${ }^{(2)}$ electrostatic selfassembly (ESA), ${ }^{(3)}$ and layer-by-layer $(\mathrm{LbL})^{(4)}$ and dip-coating ${ }^{(5)}$ techniques. Among them, the LbL self-assembly technique has been considered as the method with most potential for fabricating various types of nanoarchitecture. ${ }^{(6)}$

We have recently focused on gas sensing based on morphological changes in polyelectrolyte LbL films on optical fibres. ${ }^{(7,8)}$ For example, a long-period grating (LPG) optical fibre deposited

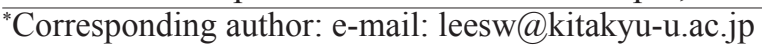


with a multilayer film of poly(acrylic acid)/poly(allyamine hydrochloride) (PAA/PAH) or PAA/ poly(diallyldimethyl ammonium chloride) (PAA/PDDA) showed high sensitivity to ammonia owing to the refractive index (RI) change in the polyelectrolyte multilayer films, where the cationic polymers play two roles in assisting the PAA assembly onto the LPG and in inducing the shrinkage of the film (film density increase) owing to the binding of amine compounds to the PAA layer.

Recently, we also have demonstrated novel chemical sensors based on the LbL multilayer mesoporous film composed of silica nanospheres $\left(\mathrm{SiO}_{2} \mathrm{NPs}\right)$ with a diameter in the range of $40-50 \mathrm{~nm}$ on LPG fibres for the detection of organic compounds ${ }^{(9)}$ and ammonia ${ }^{(10)}$ and for the measurement of the RI of substances. ${ }^{(11)}$ An additional advantage of the use of the LbL deposition technique to form the mesoporous coating, in comparison with the conventional sol-gel technique, lies in the ability to easily control the thickness of the coating layer by employing different diameters of $\mathrm{SiO}_{2} \mathrm{NPs}$. However, the porous nature of the $\mathrm{SiO}_{2} \mathrm{NP}$ coating results in a low RI, and a functional material must be infused into the mesoporous film to increase the RI of the coating.

In this study, we report a new concept of optical gas sensing based on LbL films self-assembled with positively charged gold nanoparticles $\left(\mathrm{AuNPs}^{+}\right)$and anionic polyelectrolytes. Unlike many conventional approaches based on the use of anionic gold nanoparticles, ${ }^{(12-15)}$ the AuNPs ${ }^{+}$played a role in usual cationic polymers such as PAH and PDDA; however, their high RI and unique surface plasmon resonance (SPR) enabled us to improve the sensing ability, especially for ammonia gas, using a PAA-anchored LbL film.

\section{Materials and Methods}

\subsection{Materials}

PAA (Mw ca. 4000000), poly(sodium 4-styrene sulfonate) (PSS, Mw ca. 70000), and PDDA ( $\mathrm{Mw}$ 200000-350000, $20 \mathrm{wt} \%$ in $\mathrm{H}_{2} \mathrm{O}$ ) were purchased from Sigma-Aldrich, USA. Ammonia (ca. $30 \mathrm{wt} \%$ in $\mathrm{H}_{2} \mathrm{O}$ ), hydrochloric acid $(\mathrm{HCl}, 1.0 \mathrm{M}$ ), and hydrogen tetrachloroaurate (III) tetrahydrate (99.9\%) were purchased from Wako Pure Chemical Industries, Japan. Cystamine dihydrochloride and 11-bromoundecanoic acid, which were used to synthesize a cationic disulfide, and sodium tetrahydroborate were purchased from Tokyo Kasei, Japan. All of these chemicals were reagents of analytical grade and used without further purification. Deionized pure water $(18.3 \mathrm{M} \Omega \cdot \mathrm{cm})$ was obtained by reverse osmosis followed by ion exchange and filtration (Millipore, Direct-QTM).

\subsection{Preparation of cationic gold nanoparticles}

The synthesis of a cationic disulfide $\left[\underline{\mathbf{1}},\left(-\mathrm{S}\left(\mathrm{CH}_{2}\right)_{2} \mathrm{NHCO}\left(\mathrm{CH}_{2}\right)_{10}\left(\mathrm{CH}_{3}\right)_{3} \mathrm{~N}^{+} \mathrm{Br}^{-}\right)_{2}\right]$ was carried out as described in a previous report. ${ }^{(16)}$ 1-Passivated AuNPs $\left(\right.$ AuNPs $\left.^{+}\right)$were synthesized by a method reported by Kunitake et al., as illustrated in Fig. 1. ${ }^{(17)}$ In brief, $\underline{1}(0.059 \mathrm{~g}, 0.16 \mathrm{mmol})$ was added to a $30 \mathrm{~mL}$ aqueous solution of hydrogen tetrachloroaurate (III) tetrahydrate $(0.16 \mathrm{mmol})$, and the mixture was stirred at room temperature for $5 \mathrm{~min}$. A freshly prepared aqueous solution of sodium tetrahydroborate $(5.0 \mathrm{~mL}, 0.16 \mathrm{~mol})$ was added dropwise into the mixture with vigorous stirring for $3 \mathrm{~h}$. Then, acetone $(300 \mathrm{~mL})$ was added dropwise into the mixture to remove excess disulfide until the particles precipitated. The precipitate formed was filtered off using PTFE membrane with a pore size of $0.1 \mu \mathrm{m}$ and washed with acetone to yield the $\mathrm{AuNPs}^{+}$as a black powder. 


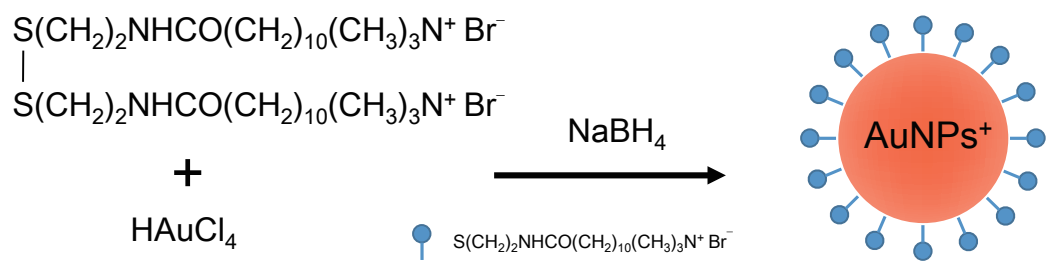

Fig. 1. (Color online) Schematic illustration of synthesis of cationic AuNPs ${ }^{+}$.

\subsection{Fabrication of LbL films and ammonia gas sensing}

Prior to deposition, quartz substrates were cleaned by air plasma treatment $(5 \mathrm{~min})$ using a plasma generator (Covance, Femto Science Co., Ltd.). The LbL method employed for AuNPs ${ }^{+} /$ polyelectrolyte alternate film deposition on the quartz substrate was similarly tried as reported in our previous work. ${ }^{(18)}$ Briefly, the substrate was immersed sequentially into a solution of positively charged AuNPs ${ }^{+}\left(1.0 \mathrm{mg} \mathrm{mL} \mathrm{m}^{-1}\right.$ in water, $\mathrm{pH}$ ca. 9.3) and into a solution of negatively charged polymer PAA (0.05 wt $\%$ in water, $\mathrm{pH}$ ca. 4.3 ) or PSS ( $0.1 \mathrm{wt} \%$ in water, $\mathrm{pH}$ ca. 7.1$)$, each for 15 min. The substrate was rinsed in distilled water and dried by flushing with nitrogen gas after each deposition step. Finally, 10-cycle films due to the LbL deposition of AuNPs $+\mathrm{PAA}^{+}$and $\mathrm{AuNPs}^{+} /$ PSS were prepared. To confirm the response to ammonia, the $\left(\mathrm{AuNPs}^{+} / \mathrm{PAA}\right)_{10}$ and $\left(\mathrm{AuNPs}^{+} / \mathrm{PSS}\right)_{10}$ films on quartz substrates were exposed to saturated ammonia gas (ca. $3000 \mathrm{ppm}$ ) vaporized from a $1 \mathrm{wt} \%$ aqueous solution of ammonia for $15 \mathrm{~min}$. After that, the films were immersed in a $0.1 \mathrm{M}$ aqueous solution of $\mathrm{HCl}$ for $15 \mathrm{~min}$ to confirm their recovery to the initial state.

Transmission electron microscopy (TEM, JEOL JEM-3010, Japan) was used to investigate the average particle size of $\mathrm{AuNPs}^{+}$under an acceleration voltage of $200 \mathrm{kV}$. In order to investigate the particle size distribution of $\mathrm{AuNPs}^{+}$, dynamic light scattering (DLS) measurements were conducted with a particle size measurement system (Otsuka Electronics, ELSZ-1000, Japan). The composition and optical responses of the films were confirmed using UV-vis spectroscopy (using a V-570 UVvis spectrophotometer; JASCO, Japan).

For Fourier transform infrared spectroscopy (FTIR) measurements, the (AuNPs $\left.{ }^{+} / \mathrm{PAA}\right)_{10}$ film was prepared on a gold-coated glass plate in a manner similar to that described above, and IR spectral changes due to the exposure to the ammonia gas were measured using a Spectrum 100 FTIR spectrometer (Perkin Elmer Japan Co., Ltd.). For FTIR assessment of the disulfide compound, $\underline{1}$ was mixed with potassium bromide $(\mathrm{KBr})$ at $1 \mathrm{wt} \%$. The $\mathrm{KBr}$ mixture was homogenized and then pressed into a transparent $\mathrm{KBr}$ pellet using a press. All data were collected at a spectral resolution of $1 \mathrm{~cm}^{-1}$.

\subsection{Surface morphology study}

The surface morphology of the prepared films was studied with a JEOL JSPM-5200 atomic force microscope (AFM) working in noncontact mode using a MicroMash NSC12/Ti-Pt/15 silicon cantilever (curvature tip radius $<40 \mathrm{~nm}$, tip length $15-20 \mu \mathrm{m}$ ). 


\section{Results and Discussion}

\subsection{LbL self-assembly of AuNPs ${ }^{+}$with polyelectrolytes}

The prepared AuNPs ${ }^{+}$were stable in water and showed a clear SPR band at $520 \mathrm{~nm}$, as shown in Fig. 2(a). From the results of DLS measurement [inset of Fig. 2(a)] and TEM observation [Fig. 2(b)], the average particle size was estimated to be ca. $5 \mathrm{~nm}$ in diameter, which is in good agreement with Refs. 16 and 17. Thus, the whole size of $\mathbf{1}$-passivated AuNPs ${ }^{+}$is estimated to be ca. $10 \mathrm{~nm}$, while the size of the gold core is $5 \mathrm{~nm} \cdot{ }^{(16,17)}$

UV-vis spectral changes due to the film deposition of $\mathrm{AuNPs}^{+}$with an alternate layer of PAA or PSS on quartz substrates are shown in Figs. 3(a) and 3(b), respectively, when the outermost layer was covered with AuNPs'. As the number of layers increases, the absorbance increases in the spectral region of 200-500 $\mathrm{nm}$. In addition, both films showed a pronounced band in the UVvis spectra at around $544 \mathrm{~nm}$ in the visible region. This absorption band linearly increased with the
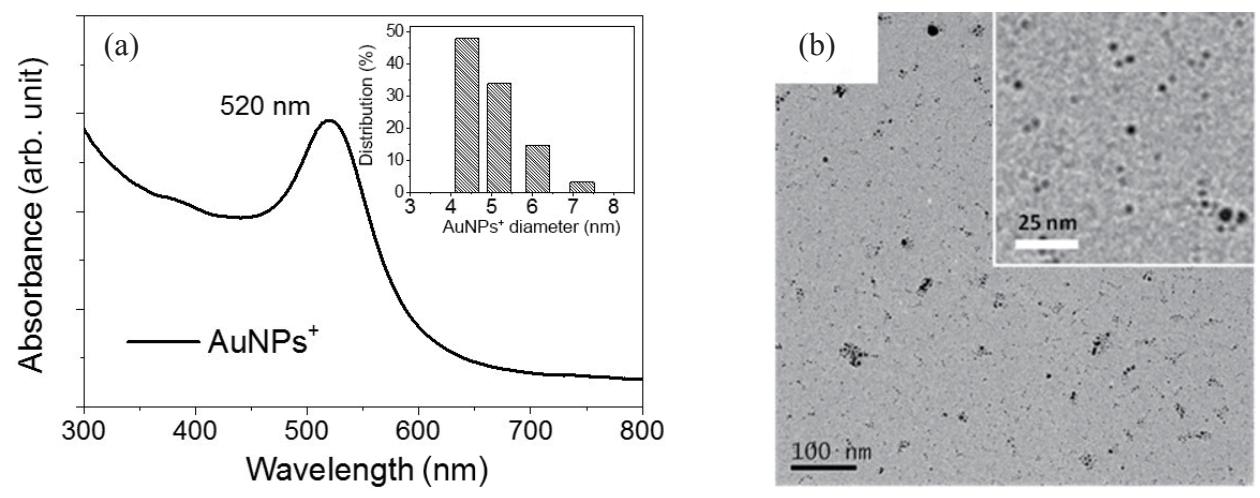

Fig. 2. (a) UV-vis spectrum of $\operatorname{AuNPs}^{+}\left(0.5 \mathrm{mg} \mathrm{mL} \mathrm{L}^{-1}\right.$ in water) and (b) TEM image of AuNPs . Inset of (a) shows the size distribution diagram of $\mathrm{AuNPs}^{+}$.

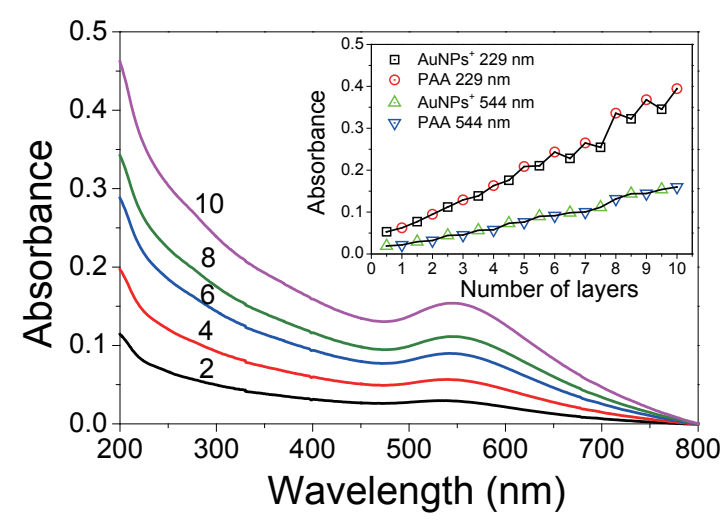

(a)

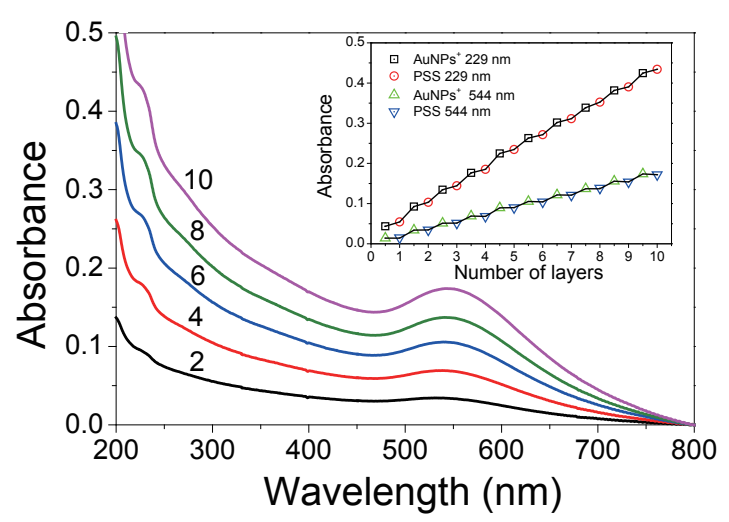

(b)

Fig. 3. (Color online) UV-vis spectral changes during the 10-cycle film deposition of $\mathrm{AuNPs}^{+}$with an alternate layer of (a) PAA or (b) PSS on quartz substrates. Insets show absorbance increases at 229 and $544 \mathrm{~nm}$. 
increase in the number of bilayers, indicating a uniform film growth on the quartz substrate. Both insets of Fig. 3 show absorbance increases measured at 229 and $544 \mathrm{~nm}$ during the film deposition.

The absorption band at $544 \mathrm{~nm}$ originates from the gold nanoparticles, AuNPs ${ }^{+}$, showing a redshift of $24 \mathrm{~nm}$ from the original SPR band (at $520 \mathrm{~nm}$ ) of $\mathrm{AuNPs}^{+}$in water. This phenomenon can be plausibly explained by the fact that the electronic (dielectric) environment of $\mathrm{AuNPs}^{+}$was considerably changed when the gold nanoparticles were covered with a PAA or PSS layer by electrostatic interaction. Consequently, the distance between the gold nanoparticles became small, leading to a redshift of the SPR absorption maximum in water. Interestingly, both the AuNPs $\mathrm{S}^{+} \mathrm{PAA}$ and $\mathrm{AuNPs}^{+} / \mathrm{PSS}$ films showed almost the same absorbance at $544 \mathrm{~nm}$ after 10 deposition cycles had been completed. This suggests that PAA may be assembled with AuNPs ${ }^{+}$via electrostatic interaction, similarly to that of PSS with AuNPs', as given in Eqs. (1) and (2). Plausibly, this may be attributed to the fact that the quaternary ammonium salt, $\mathrm{RN}^{+}\left(\mathrm{CH}_{3}\right)_{3} \mathrm{Br}^{-}$, is stable and almost unaffected by the $\mathrm{pH}$ of the solution.

$$
\begin{gathered}
\mathrm{RN}^{+}\left(\mathrm{CH}_{3}\right)_{3} \mathrm{Br}^{-}+\mathrm{R}^{\prime} \mathrm{SO}_{3}{ }^{-} \mathrm{Na}^{+} \rightleftarrows \mathrm{RN}^{+}\left(\mathrm{CH}_{3}\right)_{3}{ }^{-} \mathrm{O}_{3} \mathrm{SR}^{\prime}+\mathrm{Na}^{+} \mathrm{Br}^{-} \\
\mathrm{RN}^{+}\left(\mathrm{CH}_{3}\right)_{3} \mathrm{Br}^{-}+\mathrm{R}^{\prime} \mathrm{CO}_{2} \mathrm{H} \rightleftarrows \mathrm{RN}^{+}\left(\mathrm{CH}_{3}\right)_{3}{ }^{-} \mathrm{O}_{2} \mathrm{CR}^{\prime}+\mathrm{H}^{+} \mathrm{Br}^{-}
\end{gathered}
$$

\subsection{Ammonia gas sensing}

In the case of the AuNPs ${ }^{+} / \mathrm{PAA}$ film, UV-vis spectra, which were measured after the film was exposed to the ammonia gas vaporized from a solution of $1 \mathrm{wt} \%$ ammonia for $30 \mathrm{~min}$ and immersed in a solution of $\mathrm{HCl}$ in water $(0.1 \mathrm{M})$ for $15 \mathrm{~min}$, were reproducible, as shown in Fig. 4(a), and the absorbance changes at 299 and $544 \mathrm{~nm}$ were $0.043 \pm 0.0033$ and $0.0053 \pm 0.0013$ for five repeated tests [Fig. 4(b)], respectively. This optical change in the AuNPs ${ }^{+} / \mathrm{PAA}$ film seems to be attributable to the deprotonation or protonation of PAA, which usually induces a morphological change in the LbL multilayer films. ${ }^{(8)}$ The swelling and shrinking of the PAA polymer layers in the film might affect the SPR absorption of AuNPs ${ }^{+}$. However, no wavelength shift was observed in the SPR absorption maximum at $544 \mathrm{~nm}$. Probably this results from the close packing of AuNPs ${ }^{+}$ in the film, as predicted through the large wavelength shift of the SPR band from 520 to $544 \mathrm{~nm}$ of AuNPs'.

Figure 4(c) shows UV-vis spectra of the 10-cycle AuNPs ${ }^{+} / \mathrm{PSS}$ film after the film was exposed to the ammonia gas for $30 \mathrm{~min}$ and immersed into an aqueous solution of $\mathrm{HCl}$ for $15 \mathrm{~min}$. No significant changes were observed from the repeated tests, as shown in Fig. 4(d). This result is attributed to the absence of response of PSS to ammonia and $\mathrm{HCl}$.

\subsection{FTIR measurements}

To investigate the film composition and the binding mechanism of ammonia, FTIR measurements were carried out. Figure 5 shows FTIR spectra of the cationic disulfide, $\underline{\mathbf{1}}$, and a 10-cycle AuNPs ${ }^{+}$/PAA film before and after exposure to the ammonia gas and after $\mathrm{HCl}$ treatment. In curve (a) of Fig. 5, three unique peaks at 3296, 1639, and $1547 \mathrm{~cm}^{-1}$ correspond to the $\mathrm{N}-\mathrm{H}$ stretch and two types of $\mathrm{C}-\mathrm{O}$ stretch of the amide group (-CONH-). In addition, the peaks at 2917 and $2850 \mathrm{~cm}^{-1}$ are assigned to the $\mathrm{C}-\mathrm{H}$ stretch of the $-\mathrm{CH}_{2}-$ and $-\mathrm{N}-\mathrm{CH}_{3}$ groups of $\underline{\mathbf{1}}$, respectively. On the other hand, the peak due to the $\mathrm{C}-\mathrm{O}$ stretch of the free $-\mathrm{COOH}$ groups of PAA was observed 


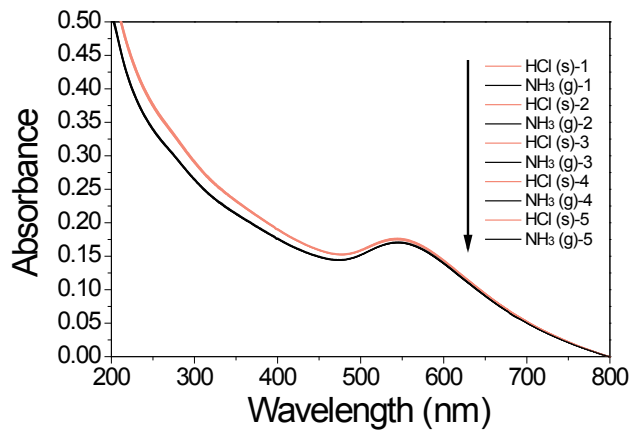

(a)

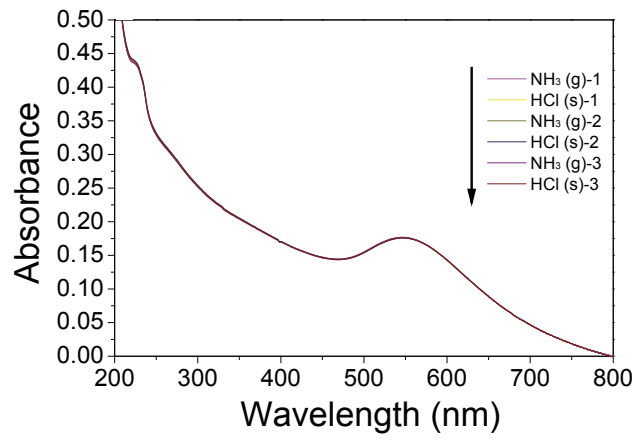

(c)

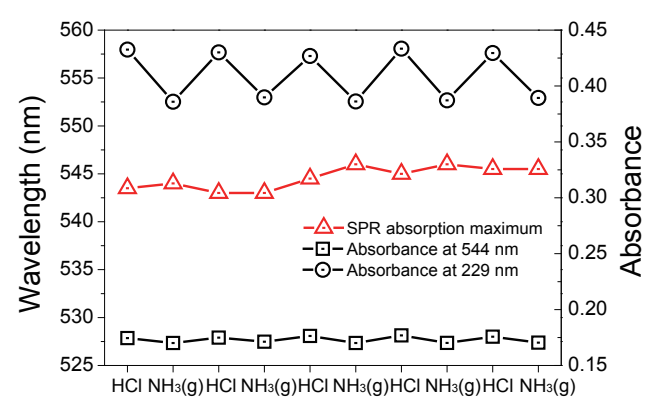

(b)

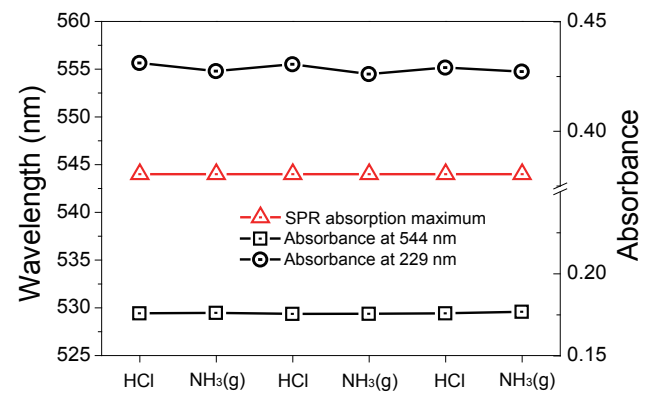

(d)

Fig. 4. (Color online) $(\mathrm{a}, \mathrm{c}) \mathrm{UV}$-vis spectra measured after the film was exposed to the ammonia gas vaporized from a solution of $1 \mathrm{wt} \%$ ammonia for $30 \mathrm{~min}$ and immersed in a solution of $\mathrm{HCl}$ in water $(0.1 \mathrm{M})$ for $15 \mathrm{~min}$ for the 10-cycle AuNPs ${ }^{+} / \mathrm{PAA}$ and AuNPs ${ }^{+} / \mathrm{PSS}$ films, respectively. (b, d) Shifts of SPR absorption maximum and absorbance changes at 299 and $544 \mathrm{~nm}$ for each film.

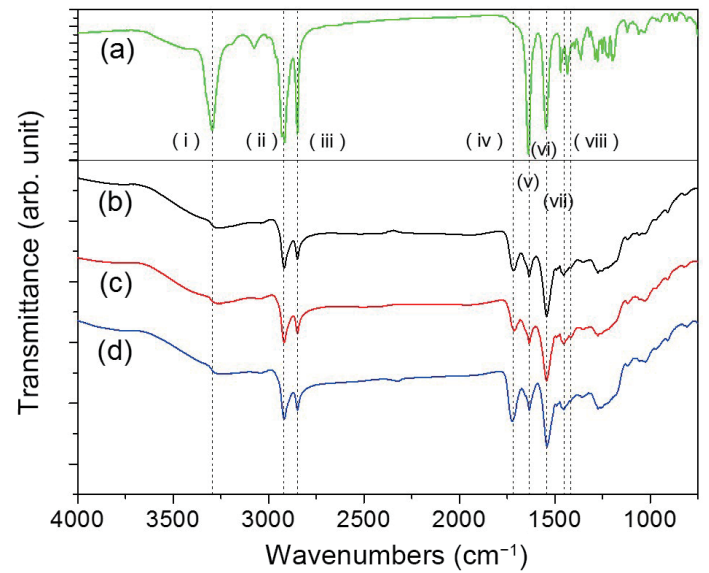

Fig. 5. (Color online) Comparison of FTIR spectra of (a) $\underline{1}$ and a 10-cycle AuNPs ${ }^{+} / \mathrm{PAA}$ film on a gold-coated glass substrate (b) before and (c) after exposure to ammonia gas and (d) after $\mathrm{HCl}$ treatment. Adopted wavenumbers: (i) 3296, (ii) 2917, (iii) 2850, (iv) 1720, (v) 1639, (vi) 1544, (vii) 1453, and (viii) $1414 \mathrm{~cm}^{-1}$.

at $1720 \mathrm{~cm}^{-1}$ along with the characteristic peaks of $\underline{1}$ in curve (b) of Fig. 5. The asymmetric and symmetric $\mathrm{C}-\mathrm{O}$ stretches of the PAA carboxylate group $\left(-\mathrm{COO}^{-}\right)$were also observed at 1544 (strong) and $1414 \mathrm{~cm}^{-1}$ (very weak), respectively. A small broad peak at around $1453 \mathrm{~cm}^{-1}$ may be attributed to the $\mathrm{C}-\mathrm{H}$ bending vibration of the $-\mathrm{CH}_{2}-$ group of $\underline{\mathbf{1}}$ and PAA. These results indicate that PAA 
was successfully employed in the LbL film and the free carboxylic acid groups of PAA remained, which can be used as selective binding sites for ammonia.

The IR spectrum of the AuNPs ${ }^{+} / \mathrm{PAA}$ film exposed to the ammonia gas is shown in curve (c) of Fig. 5. The intensity of the peak of the $\mathrm{C}-\mathrm{O}$ stretching vibration $(-\mathrm{COOH})$ at $1720 \mathrm{~cm}^{-1}$ decreased after exposure of the film to the ammonia gas. In general, the $-\mathrm{COOH}$ functional moiety undergoes transformation to the $-\mathrm{COO}^{-}$group by the acid-base reaction. However, there were no clear changes in the intensities of the peaks due to symmetric and asymmetric stretching vibrations of the $-\mathrm{COO}^{-}$group at 1414 and $1544 \mathrm{~cm}^{-1}$, respectively, as a consequence of the exposure of the film to the ammonia gas. Probably this result is attributable to the fact that the weak asymmetric $\mathrm{C}-\mathrm{O}$ stretch of the $-\mathrm{COO}^{-}$group at $1544 \mathrm{~cm}^{-1}$ overlapped with the relatively strong $\mathrm{C}-\mathrm{O}$ stretch of the amide group (-CONH-) at $1547 \mathrm{~cm}^{-1}$. In addition, the $\mathrm{C}-\mathrm{O}$ stretch of the amide group at $1570 \mathrm{~cm}^{-1}$ become stronger via hydrogen bonding between the self-assembled alkyl thiolates on the AuNPs $^{+}$. In contrast, it is observed that the other peaks of the amide group at 3296 and $1639 \mathrm{~cm}^{-1}$ were attenuated by the hydrogen bonding. Interestingly, the intensities of the peaks associated with PAA were recovered when the film was treated with $\mathrm{HCl}$, showing a decrease in transmittance at $1414 \mathrm{~cm}^{-1}$ and an increase in transmittance at $1720 \mathrm{~cm}^{-1}$, as shown in curve (d) of Fig. 5.

\subsection{Morphological study of sensing mechanism}

To clarify the UV-vis and FTIR spectral changes induced by ammonia gas adsorption and $\mathrm{HCl}$ treatment, morphological changes of the AuNPs ${ }^{+} / \mathrm{PAA}$ film were investigated. Figure 6 shows AFM images of the surface morphologies of the 10-cycle AuNPs ${ }^{+} / \mathrm{PAA}$ film recorded before and after exposure to the ammonia gas and after $\mathrm{HCl}$ treatment. The roughness of the AuNPs ${ }^{+} / \mathrm{PAA}$ film was markedly changed from $57 \mathrm{~nm}$ [Figs. 6(a) and 6(b)] to $23 \mathrm{~nm}$ [Figs. 6(c) and 6(d)] after exposure to the ammonia gas and the surface became smoother. This significant morphological change may be attributed to the aggregation of the PAA polymer layers due to the improved electrostatic

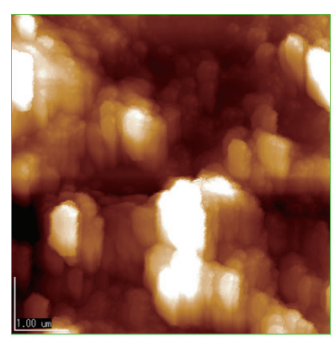

(a)

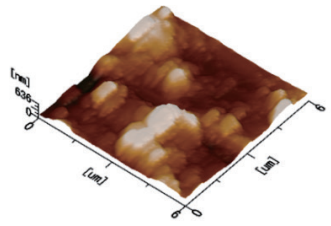

(d)

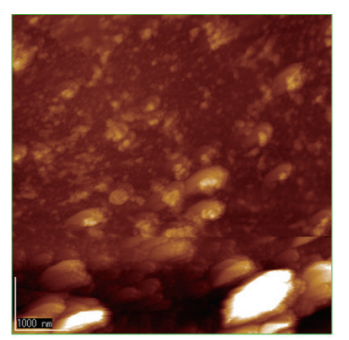

(b)

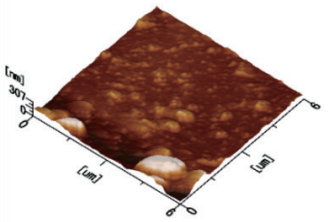

(e)

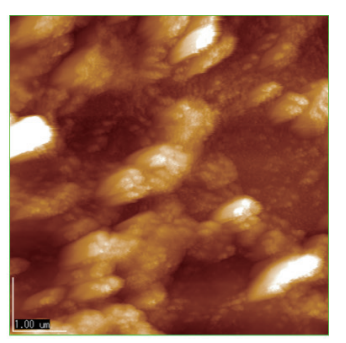

(c)

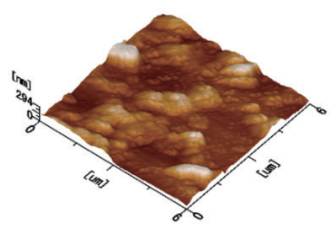

(f)

Fig. 6. (Color online) AFM images of the 10-cycle AuNPs ${ }^{+} / \mathrm{PAA}$ film (a, b) before and (c, d) after exposure to ammonia gas and (e, f) after $\mathrm{HCl}$ treatment. 
interaction with the AuNPs ${ }^{+}$. Interestingly, the original surface morphology could be recovered by $\mathrm{HCl}$ treatment [Figs. 6(e) and 6(f)]. This reveals that $\mathrm{HCl}$ treatment can be used to restore the film properties for ammonia sensing, as it was confirmed by the FTIR measurements.

In contrast, the 10-cycle AuNPs ${ }^{+} / \mathrm{PSS}$ film showed a much more uniform and smooth surface compared with that of the AuNPs ${ }^{+} / \mathrm{PAA}$ film, and there were no significant changes in the surface morphologies observed before [Figs. 7(a) and 7(b)] and after [Figs. 7(c) and 7(d)] exposure to the ammonia gas and after $\mathrm{HCl}$ treatment [Figs. 7(e) and 7(f)]. The roughness of the AuNPs ${ }^{+} / \mathrm{PSS}$ film was estimated to be ca. $10 \mathrm{~nm}$ in every case. These results are in good agreement with the UV-vis spectral changes in the AuNPs ${ }^{+} / \mathrm{PSS}$ film, indicating no response of PSS to ammonia.

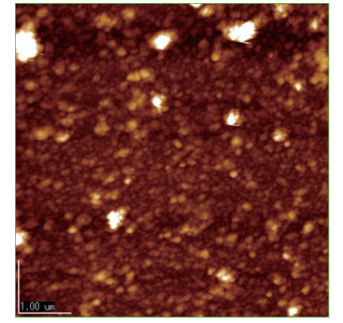

(a)

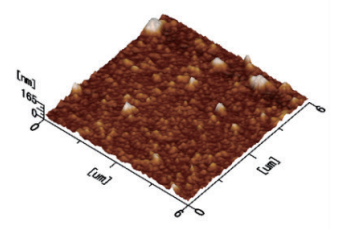

(d)

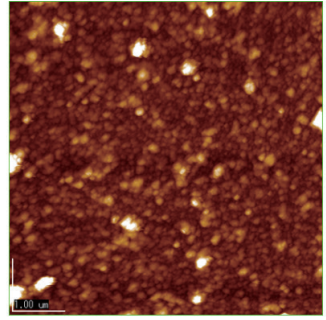

(b)

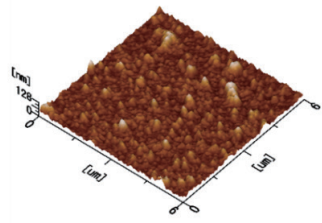

(e)

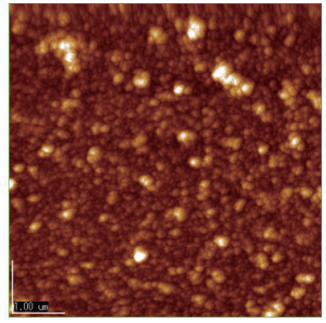

(c)

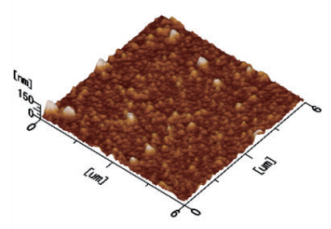

(f)

Fig. 7. (Color online) AFM images of the 10-cycle AuNPs ${ }^{+} / \mathrm{PSS}$ film (a, b) before and (c, d) after exposure to ammonia gas and (e, f) after $\mathrm{HCl}$ treatment.

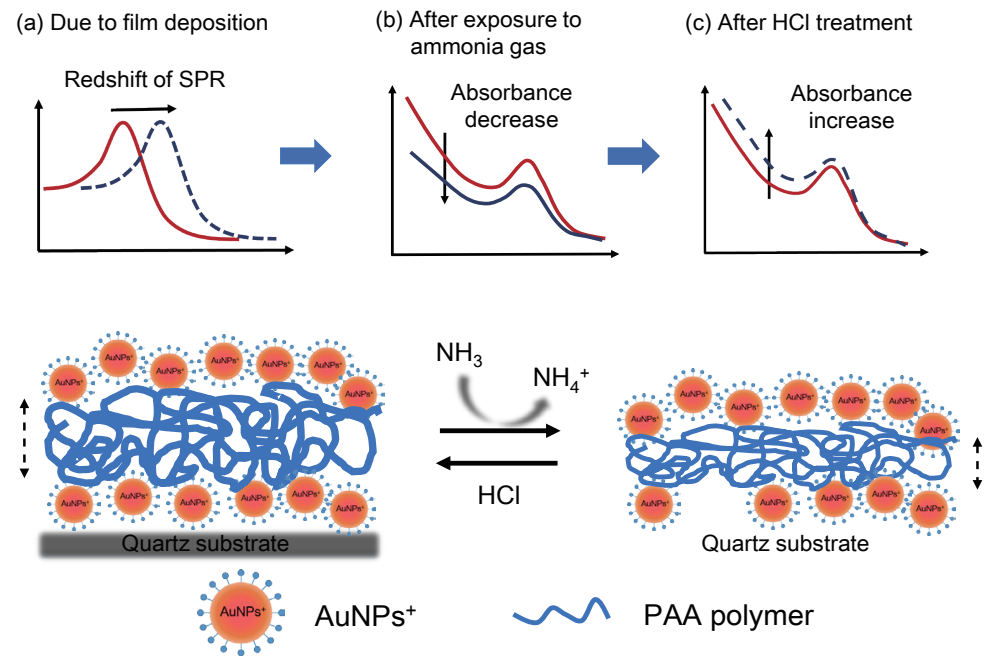

Fig. 8. (Color online) Schematic illustration of the correlation between the optical and morphological changes in the $\mathrm{AuNPs}^{+} / \mathrm{PAA}$ film due to exposure to ammonia gas and $\mathrm{HCl}$ treatment. 
The decrease in the thickness of the AuNPs ${ }^{+} / \mathrm{PAA}$ film proves our hypothesis concerning the increase in film density, as illustrated in Fig. 8. The sensing mechanism for the binding to ammonia can be considered to be based on the acid-base interaction between ammonia and the carboxylic acid moiety of PAA. As a result, the $-\mathrm{COOH}$ functional moiety undergoes transformation to $-\mathrm{COO}^{-}$ and electrostatic interactions between the PAA and AuNPs ${ }^{+}$layers can be enhanced. Similar sensing performances to those recorded when PAA was coupled with PDDA or PAH are observed. ${ }^{(7,8)}$ On the basis of the FTIR and AFM results, we can conclude that the shrinkage of the AuNPs ${ }^{+} / \mathrm{PAA}_{\mathrm{A}}$ film can be induced by the adsorption of ammonia, and this leads to a large optical change in the nearUV region, which mainly depends on the absorption of the AuNPs'.

\section{Conclusions}

In this study, we demonstrated optical gas sensing based on cationic gold nanoparticles (AuNPs ${ }^{+}$) LbL multilayer films self-assembled with anionic polyelectrolytes such as PAA and PSS. The $\mathrm{AuNPs}^{+} / \mathrm{PAA}$ film was optically sensitive to ammonia and its response was reproducible by the $\mathrm{HCl}$ treatment of the film, whereas no response was observed for the AuNPs ${ }^{+} / \mathrm{PSS}$ film. In addition, the response of the AuNPs ${ }^{+}$PAA film to ammonia could be morphologically confirmed by AFM measurements. Unfortunately, the optical response based on the SPR absorption of AuNPs ${ }^{+}$was not remarkable, which may be attributed to the close packing of AuNPs ${ }^{+}$in the film. The coverage of AuNPs $^{+}$in individual layers should be more precisely controlled to solve such a problem. Anyway, our current approach provides several possibilities for gas sensing, such as improvements in gas diffusion and electrochemical properties owing to nanoparticles, and selectivity to hydrophobic compounds owing to long alkyl thiolates self-assembled on gold nanoparticles, which will be a challenge in the near future.

\section{Acknowledgements}

This work was supported by a Grant-in-Aid for Scientific Research (A) (15H01713) from the Japan Society for the Promotion of Science. S.-W. Lee acknowledges the support of a UK Engineering and Physical Sciences Research Council Platform Grant (EP/H02252X/1).

\section{References}

1 R. Selyanchyn, S. Wakamatsu, K. Hayashi, and S. W. Lee: Sensors (Switzerland) 15 (2015) 18834.

2 X. Li, G. Zhang, X. Bai, X. Sun, X. Wang, E. Wang, and H. Dai: Nat. Nanotechnol. 3 (2008) 538.

3 S. Zhang, Y. Shao, G. Yin, and Y. Lin: J. Mater. Chem. 20 (2010) 2826.

4 Z. Tang, Y. Wang, P. Podsiadlo, and N. A. Kotov: Adv. Mater. 18 (2006) 3203.

5 Y. Lu, R. Ganguli, C. A. Drewien, M. T. Anderson, C. Jeffrey Brinker, W. Gong, Y. Guo, H. Soyez, B. Dunn, M. H. Huang, and J. I. Zink: Nature 389 (1997) 364.

6 F. Carosio, A. Di Blasio, J. Alongi, and G. Malucelli: Eur. Polym. J. 49 (2013) 397.

7 T. Wang, S. Korposh, R. Wong, S. James, R. Tatam, and S. W. Lee: Chem. Lett. 41 (2012) 1297.

8 T. Wang, S. Korposh, S. James, R. Tatam, and S. W. Lee: Sens. Actuators, B 185 (2013) 117.

9 S. Korposh, T. Wang, S. James, R. Tatam, and S. W. Lee: Sens. Actuators, B 173 (2012) 300.

10 S. Korposh, R. Selyanchyn, W. Yasukochi, S. W. Lee, S. W. James, and R. P. Tatam: Mater. Chem. Phys. 133 (2012) 784.

11 S. Korposh, S. W. James, S. W. Lee, S. Topliss, S. C. Cheung, W. J. Batty, and R. P. Tatam: Opt. Express 18 (2010) 13227.

12 S. R. Isaacs, H. Choo, W. B. Ko, and Y. S. Shon: Chem. Mater. 18 (2006) 107. 
13 Y. Bao, L. Vigderman, E. R. Zubarev, and C. Jiang: Langmuir 28 (2012) 923.

14 V. Mani, B. V. Chikkaveeraiah, V. Patel, J. S. Gutkind, and J. F. Rusling: ACS Nano 3 (2009) 585.

15 G. Peng, U. Tisch, O. Adams, M. Hakim, N. Shehada, Y. Y. Broza, S. Billan, R. Abdah-Bortnyak, A. Kuten, and H. Haick: Nat. Nanotechnol. 4 (2009) 669.

16 T. Yonezawa, S. Y. Onoue, and T. Kunitake: Chem. Lett. 10 (1999) 1061.

17 T. Yonezawa, S. Y. Onoue, and T. Kunitake: Kobunshi Ronbunshu 56 (1999) 855.

18 W. Yasukochi, T. Wang, S. Kodaira, S. Korposh, R. Selyanchyn, and S. W. Lee: Adv. Sci. Lett. 19 (2013) 415. 